\title{
The Role of Feedback in Intelligent Tutoring System
}

\author{
Jānis Dāboliņš ${ }^{1}$, Jānis Grundspeṇkisis ${ }^{2}{ }^{1-2}$ Faculty of Computer Science and Information Technology, Institute of \\ Applied Computer Science, Department of Systems Theory and Design, Riga Technical University
}

\begin{abstract}
Improvement of IT technologies, expansion of internet and popularization of web technologies have enabled technology enhanced learning introduction in adaption of general matters and acquaintance of specialized problems. It is necessary to integrate in ITS (Intelligent Tutoring System) analysis mechanisms and reactions to simulate or overcome natural tutoring environment achievements. In the development of learning systems it is necessary to take into account both individual needs and requirements, as well as the resources of information technologies. Feedback should be aligned, as much as possible, to the learner's individuality, special needs, selfevaluation, self-explanation, self-regulation, etc.
\end{abstract}

Keywords - Intelligent tutoring systems, interactive learning environments, adaptive learning, feedback, intelligent agent.

\section{INTRODUCTION}

Improvement of IT technologies, expansion of internet and popularization of web technologies have enabled technology enhanced learning introduction in adoption of general matters and acquaintance of specialized problems [1] [18] [24]. Thus research of adaption of the learning contents to e-environment has become more necessary as a result of such development. Besides, technology enhanced learning allows to choose the place and time where and when to study, which is a great advantage compared to traditional full-time education [1].

Identical educational tools and learning methods may not be effective or are less effective for all students. Use of Intelligent Tutoring Systems (ITS) allows making the learning materials more flexible, modifying educational approach according to competence and temper of the student and the learning tasks. Technology enhanced learning is the learning where self-motivation, communication, efficiency and technologies are used. ITS is the system and technologies where adaptive learning technologies are used, which helps to individualize and personalize the learning process according to individual character and needs, analyze knowledge of the theme, student's mood and emotions, as well as the learning style; typically ITS is constructed as a multi-agent systems [2]. Adaptive learning can be defined as "the process of generating a unique learning experience for each learner based on the learner's personality, interests and performance in order to achieve goals such as learner academic improvement, learner satisfaction, effective learning process and so forth".

The main goal of the paper is to research adaptive learning, Intelligent Tutoring Systems and the role of feedback in it. Research aims to find out what is necessary and important for successful learning, and what results can bring feedback. The paper also describes the main principles of the feedback integrated in ITS.

\section{II.LEARNING PROCESS, ADAPTABILITY AND FEEDBACK}

Learning, methods and student's reaction to learning are not easily definable and describable. Learning methods and successful learning results may not be defined as some particular thing, order of matters, sequence of events and thus guarantee successful outcome (student is trained and knows everything that he/she needs). That is the reason why adjustment of learning content to the student's competence is considered to be an open system problem, where adaptation capacity of the student, collaboration with learning environment as well as preferable result of the system action plays a great role (it is even hard to define the necessary outcomes, as it is not possible to fully evaluate the knowledge acquired by a person as well as and its system) [1]. In the same way it is difficult to define where the system influence on a person comes to an end.

\section{A. Learning process}

The training process can only take place in interaction with the teacher, while the teachers can be different - even a book can be considered to be a teacher, as long as the trainee has the motivation to read it and thereby learn.

The training process includes five different tasks:

1. Choosing the goals;

2. Realizing the characteristics of the learner;

3. Realizing and using the ideas about learning and learning motivation;

4. Choosing and using the ways of learning (methods and techniques);

5. Evaluating the training achievements of the learner (feedback providing) [3] [13].

Independent from the teacher, first of all it is necessary to find out the goals of the training process.

If a teacher develops a lecture, he is fully aware of the lecture goal, and similarly a learner can set a training target.

It is the learner's characteristics, which influence the ability to learn, the interests and the motivation, thereby it is important to be aware of the interests and abilities of the learner, as well as the initial knowledge, to be able to choose the appropriate teaching methods and techniques. During the learning process it is important to imagine the characteristics of the learner and to adapt the training material, methods and the process independent of the type of teacher.

The training method can be defined as collaboration between the teacher and learner, which is planned and meant to achieve the development goals of the learner.

The training methods can be divided in three main groups (Fig. 1.): 
1. Monological (the methods assume that the teaching staff is in the centre of a lecture, the content is more important than the process). The method is implemented as a lecture;

2. Dialogical (the methods suggests feedback, the learner and the process is in the centre);

3. Research (at the beginning the learner and the process are in the centre. The teaching staff plays the role of a promoter and consultant, feedback is mainly provided in the form of results, as well as during the process and the learner's self-comprehension about the achievements).

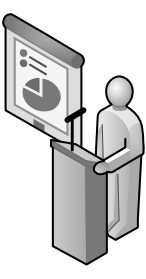

Lecture

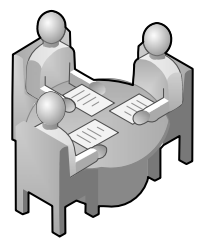

Dialog

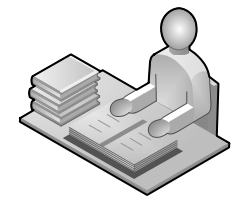

Research
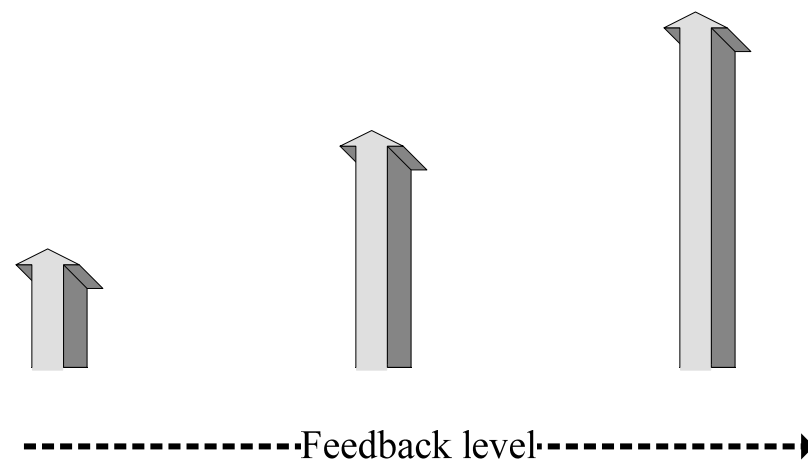

Fig. 1. Feedback level depending on the teaching method

The monological method is implemented in the form of lectures; discussions favor critical thinking and are characteristic to dialogical methods. Individual training favors self-dependent training, it is easy for the teacher to adapt to the needs of the learner; it is characteristic both to dialogical as well as monological method. Class teaching usually includes calling upon/examining and combines all of the above mentioned methods.

Setting a training goal and the ability to implement it greatly depends on the motivation of the learner. One of the motivating aspects for learners is the grade. The grade is necessary for the learner to be able to understand one's level of knowledge, while low ratings are also necessary during the training process. The grade motivates the learner to try to achieve even better results or hold on to the level. Computer games where a game is divided into levels is a good example. The player keeps the motivation and interest about the game if he receives encouraging words, as well as every executed level favors the interest to find out, what has to be done on the next level (no wonder, these games are very popular even among grownups).
The grade can be considered as the direct feedback, nevertheless different feedbacks are possible during the training process, and the goals can differ as well.

\section{B. Adaptability}

In natural environment a teacher may select each student's individual abilities, character, reaction to study material and depending on these parameters, form more or less individualized task set for each individual [12] [16] [17] [20]. It is necessary to integrate in ITS analysis mechanisms and reactions to simulate or overcome natural environment achievements [7] [21] [28].

To implement ITS, the study material has to be precise, clearly defined. It is impossible to get formal description of non-definable, illogical or emotion and mood based themes, consequently it is not possible to shape them as technology enhanced learning modules.

In the development of learning systems it is necessary to take into account individual needs and requirements as well as the resources of information technologies [6] [11] [14] [15]. It is also necessary to evaluate application of didactic materials cover learning theory matters, develop training content plan, training methods and organizational forms, all these operations would be arranged and subordinated according to their possible formalization forms for depicting and use in the ITS. It is required to include student's reaction to the learning material and analyze the chances of learning outcome stimulation. Adaptability of the ITS can be realized as the multiple forms of learning materials, feedback of the learning process and/or assessment.

The adaptability of ITS means considering the learners' knowledge about the study subject, interests and training styles [12] [10] [16]. Implementation of ITS with the possibility to allot every user content, that in best possible way meets his/her interests and desires, the individualization process is based on the two steps [4] [14]:

1. Automatic model development (user profiles) that reflect the characteristics, interests and desires of the user;

2. Automatic choice of the content based on the previously defined user model.

The individualization process is very important, therefore it is closely related to the possibility to define user profiles automatically by observing and analyzing user behavior towards the system [5] [18]. The individualization process has been successfully adapted in different applications, for instance, e-commerce infrastructure, information extraction systems, digital libraries, etc., besides, individualization process is suitable for technology enhanced learning) with the goal to identify study courses by adapting to the needs of each user.

The individualization process demands modern interpretation by the user and the resources. They have to be compatible; they should be able to define correct associations between user profiles and pedagogical content [6]. Individualization can be carried out in accordance with different features - self-initiative, goals, individual activities, social aspects, gender and age. The individualization of a user 
profile allows favoring the adaptability of ITS. Besides, learners are better motivated to work with the system that meets their needs [18] [21] [23].

\section{Feedback}

The learning process in classic understanding is teacher versus learner (fulltime studies) relationship. This learning process brings the best results on the condition that the teacher is able to respond to all the questions - provide immediate feedback.

By adapting to a particular audience, understanding its needs, a lecturer may deviate from the topic to some extent and provide an immediate feedback on the subject aspects that the audience is directly interested in, thereby broadening the knowledge of the students. It is impossible to input the whole of a teacher's knowledge into the ITS, as well as it is impossible to predict what the learner would be interested in (Fig.2).

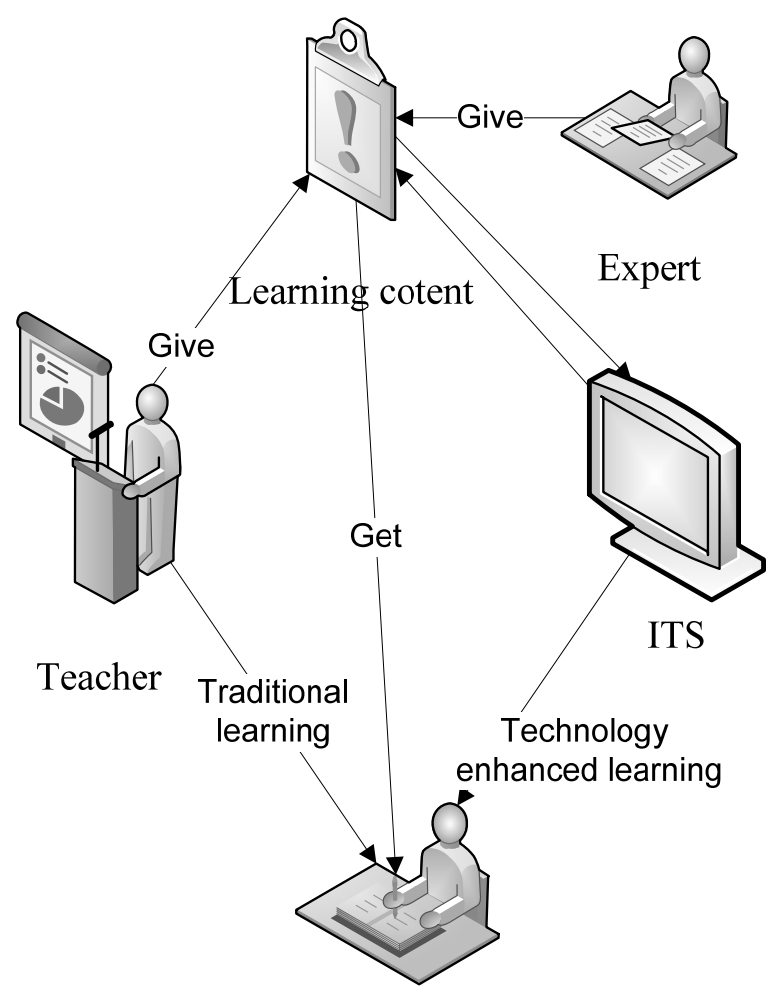

Learner

Fig. 2. Learning comparison

The dialogical teaching methods frequently apply the technique of questioning the trainee to control the level of knowledge, to understand if the learner has understood the study material correctly. This type of feedback can be integrated into ITS, thereby making sure that the learner has really mastered the material and not just guessed the previous answer.
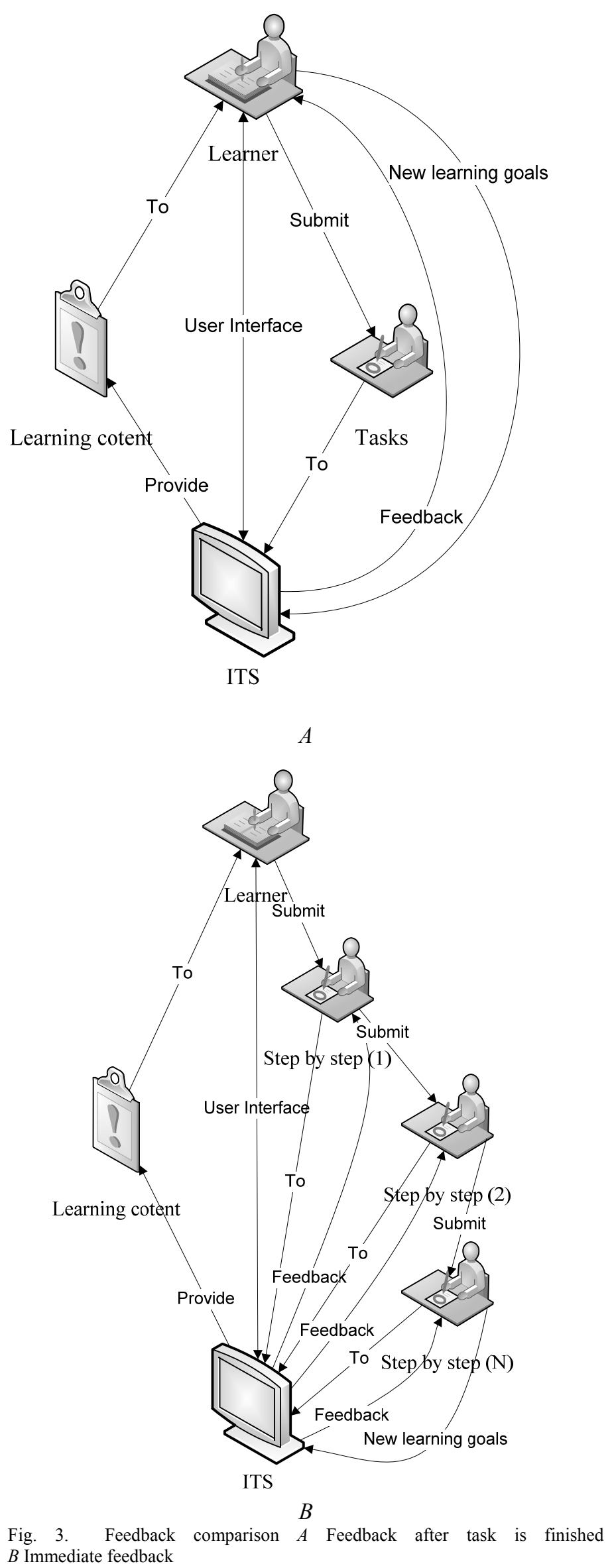
Fig. 3. Feedback comparison $A$ Feedback after task is finished
$B$ Immediate feedback 
One of the substantial components of the system is the feedback [9] [10] [25]. It can be divided into two types [7] [8] (Fig. 3):

1) Immediate feedback after completion of some particular task. An immediate response after each step is the best known version because it is the easiest to evaluate. If the trainee has completed some activity that does not conform to the data entered into the system by the expert, instant feedback is provided.

2) In its turn, if the system responds only after a task is finished, it has to have an integrated mechanism, which can evaluate the knowledge of the trainee in general.

It should be kept in mind that it is impossible to determine, which of these training mechanisms is more valuable, since each of them has certain disadvantages:

1. + The possibility to receive immediate feedback;

+ The possibility to figure out the correct answer;

+ The possibility to reduce the complexity of the task, if the trainee is not able to execute the tack independently; - No general information on the knowledge of the learner is acquired;

2. + The possibility to evaluate the level of knowledge of the learner more accurately;

+ The possibility to understand the knowledge deficiencies in a particular subject;

- If a trainee is uncertain about one of the subparagraphs, it is easy for him/her to deviate from further correct actions;

- If the task is complicated, it can take a lot of time to receive feedback.

It is typical to acquire the trainee's reaction after each activity; as a result it is very difficult to evaluate the general level of knowledge of the trainee. In the course of fulfillment of some particular task the trainee can guess further steps and the impression of the knowledge may be incorrect. The research interest of the learner can also be diminished with regard to the particular subject. Thereby greater emphasis has to be put on the significance of feedback.

\section{FORMS OF FEEDBACK}

Although all training stages are important, the most important role belongs feedback - it allows the learner himself to acquire important information on the mastered material, comprehend future tasks, and provides the teacher with the information about the learners' progress, setbacks and the required changes in the study process and subject layout [11] [26]. If the feedback between ITS and the learner is provided, better training results are achieved [29] [2] [30], if ITS instantly corrects the mistakes made by the learner or shows the right way how to avoid the mistake, knowledge of the student becomes deeper and wider [31]. Nevertheless, feedback in itself does not guarantee that the trainee will learn - feedback is the activity of the teacher/ITS, yet it does not reflect the activity of the learner. Feedback is part of the external learning process controllers (Fig. 4).

ITS offers the learner training on the system itself, introduces to the system operation, feedback types and their
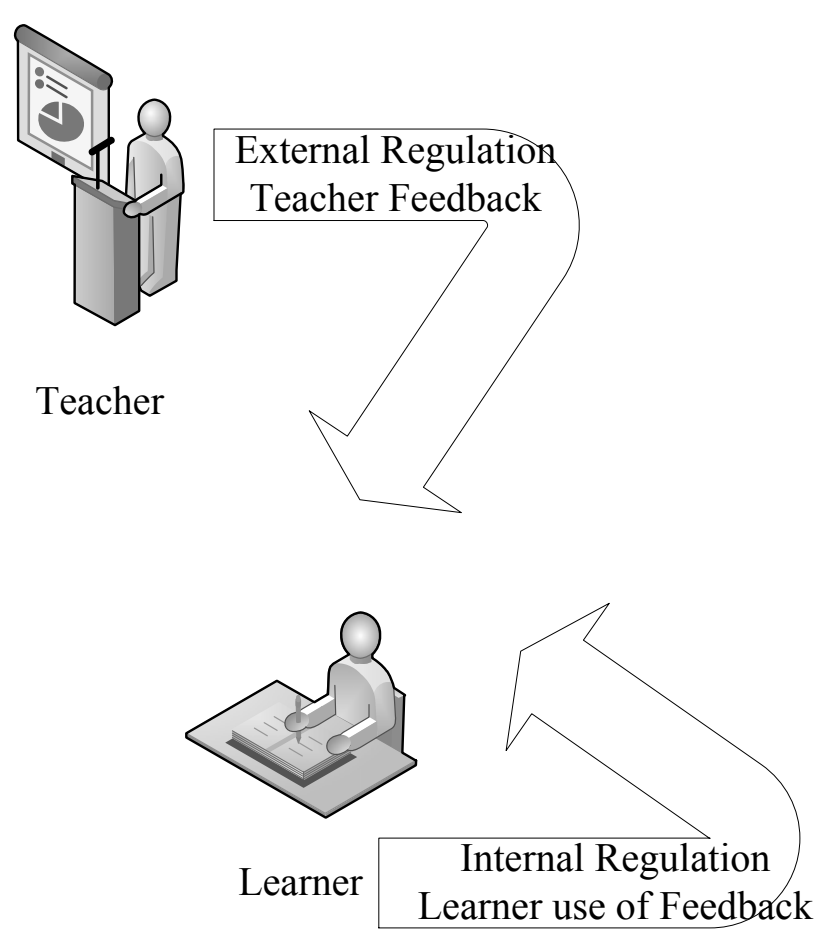

Fig. 4. A heuristic for understanding the role of teacher feedback in formative assessment and student learning [adapted from 11]

meaning, thereby favoring the understanding of the learner about ITS [16].

Effective feedback aims to [9]:

1. Assist learners in identifying their false beliefs, becoming aware of their misconceptions and inadequacies and reconstructing their knowledge.

2. Help learners to determine performance expectations, identify what they have already learned and what they are able to do and judge their personal learning progress.

3. Support learners towards the achievement of the underlying learning goals.

Feedback should be aligned, as much as possible, to the learner's individuality, special needs, self-evaluation, selfexplanation, self-regulation, etc. For assessment of the different forms of feedback ITS with the computer based concept mapping have been analyzed. The feedback in such systems is provided about the quantitative score for learner's map accompanied of how the score is obtained [2] [8] [9] [19].

Feedback in the ITS is implemented as the informative (text-based form or graphics-based form), tutoring (text-based form or dialog-based form) and student's feedback (dialoguebased form).

Feedback can be direct and indirect, as well as positive and negative. Positive feedback ("good news") implicitly has greater importance in motivating the learner, since humans have the tendency to focus on good things, motivate themselves by praise and positive affirmations. Negative feedback ("bad news"), however, can be valuable in 
motivating and promoting the learning process, shaping an idea about the abilities of the learner [19] [22] [27].

The basic concept of IKAS (Intelligent Knowledge Assessment System developed at the Department of Systems Theory and Design of Riga Technical University) is exercises for knowledge assessment, where natural language processing is not necessary for computerized assessment, as well as involvement of the teaching staff in the competence evaluation process. Concept map exercises are different and thus adjustable to various knowledge assessment needs (more simple or more complicated exercises). Besides variety of exercises founded in concept maps and arranging possibility after level of difficulty, allows adjusting them to adaptive knowledge assessment [2]. The system COMPASS (COncept $\mathrm{MaP}$ ASSessment and learning environment) is the disciplineindependent concept mapping learning environment developed at the Educational \& Language Technology Laboratory of the Department of Informatics \& Telecommunications at the University of Athens. Analysis of the map is based on the assessment of the propositions according to specific criteria, such as completeness, accuracy, superfluity, missing out and non-recognizability, results into the identification of specific error categories (e.g. incomplete relationship, incorrect concept, superfluous relationship, missing proposition), and is discriminated in the qualitative and quantitative analysis. The qualitative analysis is based on the qualitative characterization of the errors and aims to contribute to the qualitative diagnosis of student's knowledge; that is student's incomplete understanding/ beliefs and false beliefs. The aim of the quantitative analysis is to evaluate the level of student's knowledge and is based on the weights assigned to each error category as well as to each concept and proposition that appear on expert map, reflecting their degree of importance. Pre-defined weights for error categories are supported; the teacher has the possibility to personalize the assessment process and configure the weights [9]. Both mentioned systems provide highly valued feedback (more [7] and [9]).

\section{CONCLUSIONS}

Feedback has the most important role in the study process, besides it is one of the main adaptability possibilities of ITS. Through feedback the learner gets the possibility to understand what he/she already knows and what is able to accomplish, what activities are necessary for the further learning process. In order to learn, the learner ought to understand the learning goal, to recognize one's present level of knowledge with regard to learning goals and should learn to improve the knowledge. Thereby feedback can be the basis of further cognition process and motivation of the learner.

The information provided by ITS and/or the teacher to the learner about how his/her work, achievements and study results compare to the study goals, is external information reaches the learner as an external feedback. Learning takes place when the learner turns attention to the study goals, uses the obtained feedback and focuses on acquiring a subject, phenomenon or concept, to improve one's knowledge. The learner learns only when the inner learning self-adjustment, inner feedback, take place.

The existing feedback mechanisms integrated into ITS allow receiving feedback after a complete test in the studied subject - gaining confidence on the quality and entity of the mastered subject, as well as step by step - by performing the tasks with the system in the form of a dialog, where feedback is provided after completion of each step.

The topic studied in the paper is very relevant to the concept of blended learning. Blended learning is a formal education program, in which a student learns at least partially through online delivery of the content and instruction with some element of student control over time, place, path, and/or pace [32]. Blended learning is the form of education that combines face-to-face classroom methods with computermediated activities. According to its proponents, the strategy creates a more integrated approach for both instructors and students.

The terms "blended," "hybrid," "technology-mediated instruction," "web-enhanced instruction," and "mixed-mode instruction" are often used interchangeably in modern research literature. However, recent researchers in the United States tend to use the term "blended learning" with more regularity [33]. Research described in this paper explains the role of feedback in ITS, as such systems can be used in several technology enhanced learning methods and approaches including blended learning.

This work has been partly supported by the European Social Fund within the project "Support for the implementation of doctoral studies at Riga Technical University".

\section{REFERENCES}

[1] P. Phobun and J. Vicheanpanya, “Adaptive intelligent tutoring systems for e-learning systems," Procedia - Social and Behavioral Sciences, Volume 2, Issue 2, pp 4064-4069, 2010.

[2] A. Anohina-Naumeca and J. Grundspenkis, "Evaluating Students' Concept Maps in the Concept Map Based Intelligent Knowledge Assessment System," Proceedings of the 13th East European Conference, ADBIS, Latvia, Riga, pp 8-15, 2010

[3] Gage, N.L. and Berliner, D.C. (Geidžs, N.L. and Berliners, D.C.),1999. Pedagogiskā psihologíja/ Educational psychology Zvaigzne ABC, Riga. 662 Pages.

[4] C.Mencar, C.Castiello and A.M.Fanelli Fuzzy User Profiling in eLearning Contexts; Book Chapter; Lecture Notes in Computer Science, 2008, Volume 5178, Knowledge-Based Intelligent Information and Engineering Systems, Pages 230-237

[5] Latham, A. et.al. 2011. A conversational intelligent tutoring system to automatically predict learning styles. In Computers \& Education, pp 115

[6] Kort, B. et.al., 2001. An Affective Model of Interplay Between Emotions and Learning: Reengineering Educational Pedagogy-Building a Learning Companion. Proceedings of ICALT Massachusetts, USA, pp. $43-48$

[7] A.Anohina Adaptīvas apmācības un zināšanu vērtēšanas intelektuāla atbalsta sistēmas izstrādāšana Promocijas darbs Rīgas Tehniskā universitāte, Datorzinātnes un informācijas tehnologijas fakultāte, Lietiškso datorsistēmu institūts; Rīga 2007

[8] Grundspenkisis, J. Usage Experience and Student Feedback Driven Extension of Functionality of Concept Map Based Intelligent Knowledge Assessment System In Communication \& Cognition. 2010Volume 43. pp $1-20$.

[9] E.Gouli, et.al. "How COMPASS supports multi-feedback forms \& components adapted to learner's characteristics" In: P.Goodyear, D.G.Sampson, D. Yang, Kinshuk, T. Okamoto, R. Hartley and N-S. Chen (Eds.)Proceedings of the 5th IEEE International Conference on 
Advanced Learning Technologies (ICALT2005), (Kaohsiung, Taiwan, July 5-8), 424-428, 2005

[10] N.Jones, P.Georghiades and J.Gunson Student feedback via screen capture digital video: stimulating student's modified action Journal Article Higher Education, 2012, Volume 64, Number 5, Pages 593-607

[11] S.M. Brookhart Teacher Feedback in Formative Classroom Assessment Book Chapter; Studies in Educational Leadership, 1, Volume 15, Leading Student Assessment, Pages 225-239; 2012

[12] C.Limongelli, F.Sciarrone, M.Temperini and G.Vaste Lecomps5: A Framework for the Automatic Building of Personalized Learning Sequences Book Chapter Lecture Notes in Computer Science, 2008 , Volume 5288, Emerging Technologies and Information Systems for the Knowledge Society, Pages 296-303

[13] Bloom, B.S.: Taxonomy of Educational Objectives. David McKay Company Inc. (1964)

[14] A.Lorenz Agent-Based Ubiquitous User Modeling Book Chapter Lecture Notes in Computer Science, 2005, Volume 3538, User Modeling 2005, pp 150-153

[15] C. Limongelli, F.Sciarrone and G.Vaste LS-PLAN : An Effective Combination of Dynamic Courseware Generation and Learning Styles in Web-Based Education Book Chapter Lecture Notes in Computer Science, 2008, Volume 5149, Adaptive Hypermedia and Adaptive WebBased Systems, Pages 133-142

[16] N. Medina-Medina, F. Molina-Ortiz, L. García-Cabrera and J. ParetsLlorca Personalized Guided Routes in an Adaptive Evolutionary Hypermedia System Book Chapter Lecture Notes in Computer Science, 2003, Volume 2809, Computer Aided Systems Theory - EUROCAST 2003, Pages 196-207

[17] A. Pedrero, V. Alonso, M.A. Villarroel, P. de la Fuente and A.S. Cabaco Presentation Adaptation: Results from a Case Study Book Chapter 2009, Engineering the User Interface, Pages 1-13

[18] I. -Han Hsiao and P. Brusilovsky Motivational Social Visualizations for Personalized E-Learning Book Chapter Lecture Notes in Computer Science, 2012, Volume 7563, 21st Century Learning for 21st Century Skills, Pages 153-165

[19] D. H. Lee and P. Brusilovsky Reinforcing Recommendation Using Implicit Negative Feedback Book Chapter Lecture Notes in Computer Science, 2009, Volume 5535, User Modeling, Adaptation, and Personalization, Pages 422-427

[20] P.Brusilovsky and N. Henze Open Corpus Adaptive Educational Hypermedia Book Chapter Lecture Notes in Computer Science, 2007, Volume 4321, The Adaptive Web, Pages 671-696

[21] P Brusilovsky Adaptive Hypermedia Journal Article User Modeling and User-Adapted Interaction, 2001, Volume 11, Numbers 1-2, Pages 87110

[22] T. D. Loboda and P. Brusilovsky Adaptation in the Context of Explanatory Visualization Book Chapter Lecture Notes in Computer Science, 2008, Volume 5192, Times of Convergence. Technologies Across Learning Contexts, Pages 250-261

[23] H.Ashman, T.Brailsford and P.Brusilovsky Personal Services: Debating the Wisdom of Personalisation Book Chapter Lecture Notes in Computer Science, 2009, Volume 5686, Advances in Web Based Learning - ICWL 2009, Pages 1-11

[24] P. Brusilovsky and E. Millán User Models for Adaptive Hypermedia and Adaptive Educational Systems Book Chapter Lecture Notes in Computer Science, 2007, Volume 4321, The Adaptive Web, Pages 3-53

[25] Y. Gong, J.E. Beck and C. Ruiz Modeling Multiple Distributions of Student Performances to Improve Predictive Accuracy Book Chapter
Lecture Notes in Computer Science, 2012, Volume 7379, User Modeling, Adaptation, and Personalization, Pages 102-113

[26] L.Peska User Feedback and Preferences Mining Book Chapter Lecture Notes in Computer Science, 2012, Volume 7379, User Modeling, Adaptation, and Personalization, Pages 382-386

[27] M. Dennis, J. Masthoff and C. Mellish Adapting Performance Feedback to a Learner's Conscientiousness Book Chapter Lecture Notes in Computer Science, 2012, Volume 7379, User Modeling, Adaptation, and Personalization, Pages 297-302

[28] M. S. Desarkar, R. Saxena and S. Sarkar Preference Relation Based Matrix Factorization for Recommender Systems Book Chapter Lecture Notes in Computer Science, 2012, Volume 7379, User Modeling, Adaptation, and Personalization, Pages 63-75

[29] He, Y., et.al. 2009. Automatic summary assessment for intelligent tutoring systems. In Computers \& Education, Volume 53, Issue 3, pp 890-899

[30] Roll, I., et.al., 2011. Improving students' help-seeking skills using metacognitive feedback in an intelligent tutoring system. In Learning and Instruction, Volume 21, Issue 2, pp 267-280

[31] Woo Woo C., et.al., 2006. An intelligent tutoring system that generates a natural language dialogue using dynamic multi-level planning. In Artificial Intelligence in Medicine, Volume 38, Issue 1, pp 25-46

[32] Heather Staker and Michael B. Horn 2012. Classifying K-12 Blended Learning Pages 1-22

[33] Martyn, Margie 2003. The hybrid online model: Good practice. Educause Quarterly: pp.18-23.

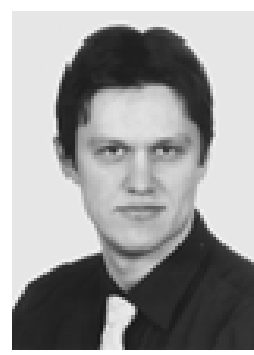

Jānis Dāboliṇš Mg.sc.ing. (comp.) PhD student, Lecturer, Researcher

Design of applied multi-agent systems, development and optimization of data base and its structure, IT systems, CAD/CAM systems in product design, innovative Technologies.

Riga Technical university, Faculty of Computer Science and Information Technology, Institute of Applied Computer Science, Department of Systems Theory and Design, Phone: +371 29165893, E-mail: janis.dabolins@rtu.lv

Jānis Grundspeṇkis Professor., Dr.habil.sc.ing.

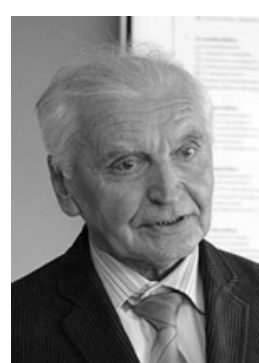
(comp.), Head of the Department of Systems Theory and Design; Director of the Institute of Applied Computer Systems; Dean of the Faculty of Computer Science and Computer Systems Knowledge Acquisition, Knowledge Representation, Hybrid Knowledge - Based Systems, Temporal Knowledge Bases, Causal Domain Models, Structural Modelling, Intelligent Systems..

Riga Technical University Faculty of Computer Science and Information Technology, Institute of Applied Computer Science, Department of Systems Theory and Design, Phone: +371 67089529, E-mail: janis.grundspenkis@rtu.lv . 